First Generation Toolset for Calculation of Induced Seismicity Hazard Profiles

W. Foxall, L. Hutchings, S. Johnson, J. Savy

November 28, 2012 
This document was prepared as an account of work sponsored by an agency of the United States government. Neither the United States government nor Lawrence Livermore National Security, LLC, nor any of their employees makes any warranty, expressed or implied, or assumes any legal liability or responsibility for the accuracy, completeness, or usefulness of any information, apparatus, product, or process disclosed, or represents that its use would not infringe privately owned rights. Reference herein to any specific commercial product, process, or service by trade name, trademark, manufacturer, or otherwise does not necessarily constitute or imply its endorsement, recommendation, or favoring by the United States government or Lawrence Livermore National Security, LLC. The views and opinions of authors expressed herein do not necessarily state or reflect those of the United States government or Lawrence Livermore National Security, LLC, and shall not be used for advertising or product endorsement purposes.

This work performed under the auspices of the U.S. Department of Energy by Lawrence Livermore National Laboratory under Contract DE-AC52-07NA27344. 


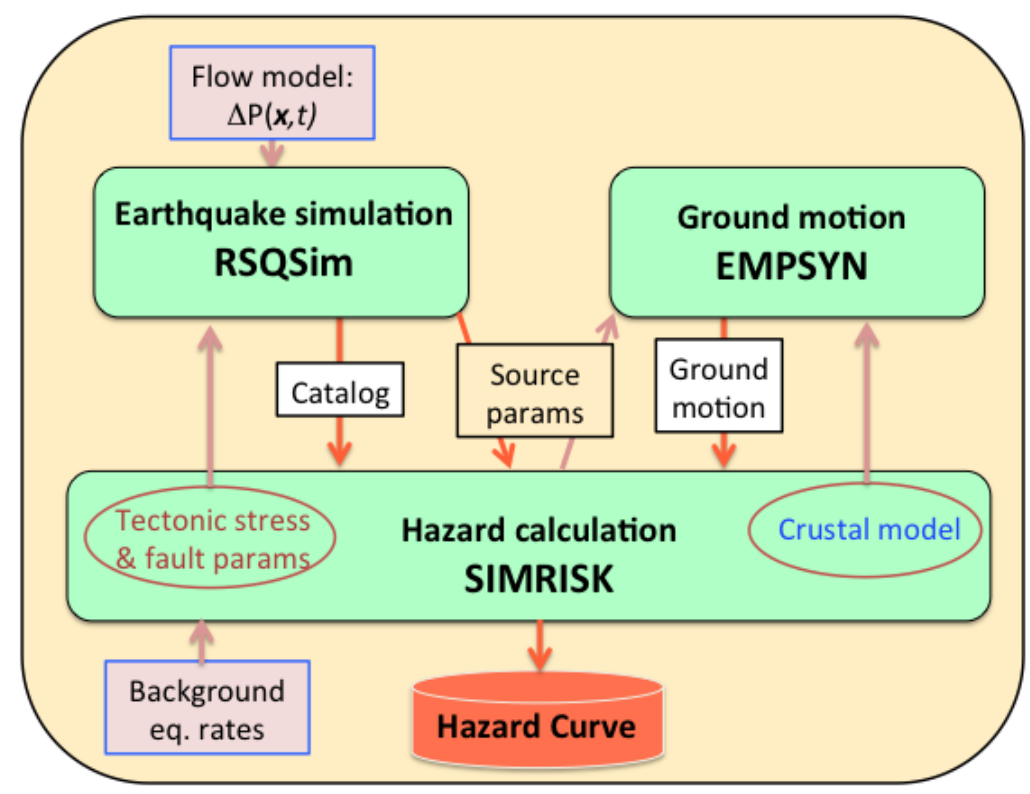

First-Generation Toolset for Calculation of Induced Seismicity Hazard Profiles

17 January 2013 


\section{Disclaimer}

This report was prepared as an account of work sponsored by an agency of the United States Government. Neither the United States Government nor any agency thereof, nor any of their employees, makes any warranty, express or implied, or assumes any legal liability or responsibility for the accuracy, completeness, or usefulness of any information, apparatus, product, or process disclosed, or represents that its use would not infringe privately owned rights. Reference therein to any specific commercial product, process, or service by trade name, trademark, manufacturer, or otherwise does not necessarily constitute or imply its endorsement, recommendation, or favoring by the United States Government or any agency thereof. The views and opinions of authors expressed therein do not necessarily state or reflect those of the United States Government or any agency thereof.

Cover Illustration: Schematic representation of the National Risk Assessment Partnership (NRAP) computational framework for calculating probabilistic seismic hazard for induced seismicity.

Suggested Citation: Foxall, W.; Hutchings, L.; Johnson, S.; Savy, J. First-Generation

Toolset for Calculation of Induced Seismicity Hazard Profiles; NRAP-TRS-III-002-2013; NRAP Technical Report Series; U.S. Department of Energy, National Energy Technology Laboratory: Morgantown, WV, 2012; p 16.

An electronic version of this report can be found at: www.netl.doe.gov/nrap 


\title{
First-Generation Toolset for Calculation of Induced Seismicity Hazard Profiles
}

\author{
William Foxall, \\ Lawrence Hutchings ${ }^{2}$, Scott Johnson ${ }^{1}$, and Jean Savy ${ }^{1,3}$ \\ ${ }^{1}$ Atmospheric, Earth and Energy Division, Lawrence Livermore National Laboratory, 7000 \\ East Avenue, Livermore, CA 94551 \\ ${ }^{2}$ Earth Sciences Division, Lawrence Berkeley National Laboratory, 1 Cyclotron Road, \\ Berkeley, CA 94720 \\ ${ }^{3}$ Savy Risk Consulting, 733 Arimo Avenue, Oakland, CA 94610 \\ NRAP-TRS-III-002-2013 \\ Level III Technical Report Series
}

17 January 2013 
This page intentionally left blank. 


\section{Table of Contents}

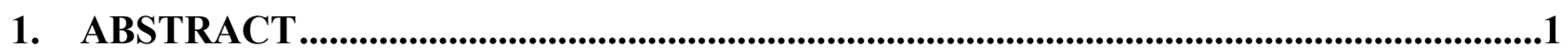

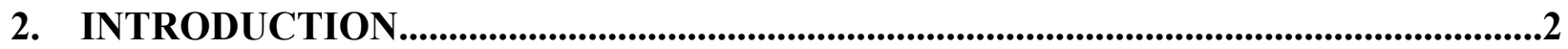

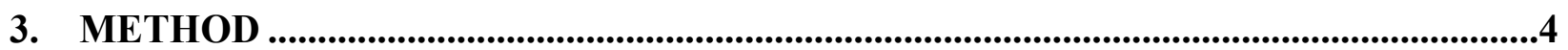

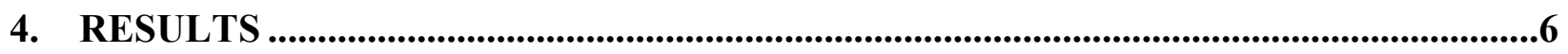

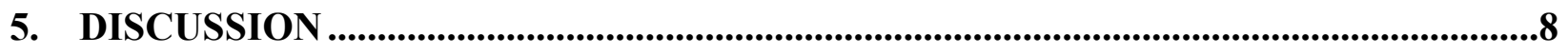

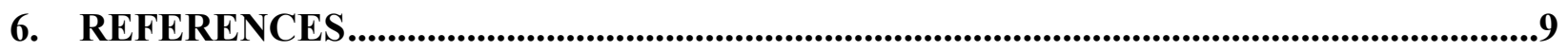




\section{List of Figures}

Figure 1: Schematic diagram of the probabilistic seismic hazard computational framework.

Figure 2: Fault geometry showing pore pressure distributions before (hydrostatic) and at the peak of injection.

Figure 3: Seismic hazard curve at a surface site approximately $5 \mathrm{~km}$ from the fault. .7

\section{List of Tables}

Table 1: Earthquake source and ground motion simulation parameter values 


\section{Acronyms and Abbreviations}

\begin{tabular}{|l|l|}
\hline \multicolumn{1}{|c|}{ Term } & \multicolumn{1}{c|}{ Description } \\
\hline$\mu_{0}$ & Base coefficient of friction \\
\hline$\lambda$ & Elastic Lame parameter \\
\hline$\mu$ & Elastic shear modulus \\
\hline$\sigma$ & Fault normal stress \\
\hline$\tau$ & Fault shear stress \\
\hline $\mathrm{A}$ & Rate-and-state friction direct effect parameter (e.g. Marone, 1998) \\
\hline $\mathrm{b}$ & Rate-and-state evolution parameter \\
\hline $\mathrm{d} \sigma / \mathrm{dz}$ & Normal stress gradient \\
\hline $\mathrm{D}_{\mathrm{c}}$ & Rate-and-state slip-weakening distance \\
\hline DOE & Department of Energy \\
\hline $\mathrm{g}$ & Gravitational acceleration $=9.81$ m.s s $^{-2}$ \\
\hline $\mathrm{GCS}$ & Geological carbon storage \\
\hline LBNL & Lawrence Berkeley National Laboratory \\
\hline LLNL & Lawrence Livermore National Laboratory \\
\hline $\mathrm{M}$ & Earthquake magnitude \\
\hline NRAP & National Risk Assessment Partnership \\
\hline PSHA & Probabilistic seismic hazard analysis \\
\hline PSRA & Probabilistic seismic risk assessment \\
\hline USGS & U.S. Geological Survey \\
\hline V & Long-term fault slip rate \\
\hline$V_{\text {eq }}$ & Coseismic fault slip velocity \\
\hline $\mathrm{v}_{\mathrm{p}}$ & Crustal P-wave velocity \\
\hline $\mathrm{v}_{\mathrm{s}}$ & Crustal S-wave velocity \\
\hline
\end{tabular}




\section{Acknowledgments}

This work was completed as part of National Risk Assessment Partnership (NRAP) project. Support for this project came from the Department of Energy's (DOE) Office of Fossil Energy's Crosscutting Research program. The authors wish to acknowledge Robert Romanosky (NETL Strategic Center for Coal) and Regis Conrad (DOE Office of Fossil Energy) for programmatic guidance, direction, and support.

The authors also wish to acknowledge Prof. Jim Dieterich and Dr. Keith Richards-Dinger at the University of California, Riverside for making the RSQSim earthquake simulation program available to us and for their continued interest and support, and John Douglas of Le Bureau de Recherches Géologiques et Minières, France, for making a preprint of his paper available. 


\section{ABSTRACT}

The National Risk Assessment Partnership (NRAP) is developing a science-based toolset for the analysis of the potential risks associated with induced seismicity resulting from $\mathrm{CO}_{2}$ injection. The toolset adapts the standard Probabilistic Seismic Risk Assessment (PSRA) approach that is widely applied to estimating the risk of structural damage from naturally occurring earthquakes. The work described in this report focused on developing the first-generation framework for Probabilistic Seismic Hazard Assessment (PSHA), the first component of the risk toolset. The results presented demonstrate the application of the PSHA methodology to generate a seismic hazard curve for hypothetical faulting scenario that is based on a realistic $\mathrm{CO}_{2}$ storage reservoir. The next steps are to apply the toolset to a range of model conditions to assess hazard sensitivity to key parameters, to further develop the capability to estimate of hazard over widely different intervals of time, and to carry out full suites of realizations to generate full hazard uncertainty estimates. 


\section{INTRODUCTION}

It is well known that injecting fluids into the upper layers of the Earth's crust can induce earthquakes to occur under certain conditions. Indeed, small seismic events recorded by sensitive surface and downhole geophones are routinely used to monitor fluid movement during injection operations. However, under some conditions, injection operations have produced sufficiently large seismic events to cause ground motion that is felt at the Earth's surface. Although this ground motion is usually well below a level that poses a risk to surface structures, $\mathrm{CO}_{2}$ storage operations aim to avoid any conditions that could cause felt ground-motion events. Therefore, the National Risk Assessment Partnership (NRAP) is developing a science-based toolset for the analysis of the potential risks associated with induced seismicity resulting from $\mathrm{CO}_{2}$ injection.

A methodology is being developed for induced seismicity risk by adapting the standard Probabilistic Seismic Risk Assessment (PSRA) approach that is widely applied to estimating the risk of structural damage from naturally occurring tectonic earthquakes. PSRA involves coupling the probability of an event occurring with the consequences of that event, and it is generally carried out using the following procedure:

1. Characterize the locations and sizes of earthquake sources (faults and fractures). The size of each source determines the maximum earthquake magnitude $(\mathrm{M})$ that it can generate.

2. Estimate the average frequencies of occurrence of earthquakes of different magnitudes for each source.

3. Calculate the ground motions resulting from the earthquakes on each source at sites of interest. Ground motion parameters generally include ground velocity and acceleration at specified frequencies, which are functions of source magnitude and source-site distance.

4. Calculate the hazard curve. This gives the annual probability of exceeding given ground motion values, and is calculated by integrating the ground motions generated on all of the sources.

5. Calculate the risk, which is the annual probability of a given consequence, such as a specified degree of structural damage. This is accomplished by multiplying the hazard curve with a vulnerability function that expresses the probability of the consequence for each ground motion value.

In standard PSRA, Step 2 is done empirically by statistical analysis of the frequencies of occurrence of past natural earthquakes in a region. For induced earthquakes, however, an empirical dataset of events can exist only after injection is ongoing, so standard PSRA methods cannot be applied. Hence, NRAP is using physics-based modeling to develop simulated seismicity datasets based on regional tectonics, local geology and fluid injection depths, rates and pressures.

NRAP is presently focused on developing an integrated framework for computing the first four steps in the procedure, which are collectively referred to as Probabilistic Seismic Hazard Analysis (PSHA). Standard PSHA is used, for example, by the U.S. Geological Survey (USGS) to produce the National Seismic Hazard Maps. This report describes the initial development of the PSHA toolset for fluid-induced seismicity and a demonstration end-to-end hazard calculation for a representative geological carbon storage (GCS) scenario. 
Induced seismicity may include small events that do not pose a risk to surface structures but that are felt in nearby communities; as such, these small events may pose a risk of negative public perception. Therefore, NRAP's first-generation toolset includes consideration of induced earthquakes as small as M1.5; such events may occur relatively frequently at depths of a few kilometers but can be felt only at short distances. These events are significantly smaller than the minimum magnitude of M4.5, usually considered in standard seismic risk analysis.

As noted above, in conventional applications of PSHA the frequency-magnitude statistics needed in Step 2 are empirically derived from regional catalogs of past earthquakes. In contrast, the PSHA method being developed by NRAP for induced seismicity approaches Step 2 through simulation for the following two reasons: first, prior to injection at a site, the empirical seismicity catalog obviously cannot include induced events; and second, conventional PSHA generally assumes that earthquake occurrence probabilities are uniform in both time and space, whereas the occurrence of fluid-induced earthquakes is inherently linked to the time- and spacedependent evolution of the pore pressure field. The NRAP PSHA method is being developed for risk assessment beginning at the design and planning phase of a GCS project. Hence, NRAP's PSHA approach presently utilizes computational methods to generate seismicity catalogs by simulating earthquakes induced by elevated pore pressures input from a fluid flow model. In addition, physically-based ground motion calculations are employed in Step 3 because existing generic empirical relations used in conventional PSHA are very poorly constrained for small events at short distances. However, the NRAP PSHA framework has been designed to accommodate alternative frequency-magnitude and ground motion modules, as described in Section 3 below. 


\section{METHOD}

NRAP's simulation-based PSHA toolset is illustrated schematically in Figure 1. The computational framework couples the hazard estimation module, SIMRISK, with the earthquake simulation code RSQSim and the ground-motion simulation module EMPSYN. SIMRISK is a Fortran computer program that is being developed by NRAP specifically for induced seismicity PSHA. RSQSim (Dieterich and Richards-Dinger, 2010; Richards-Dinger and Dieterich, 2012) is a $C$ program written and made available to us by Jim Dieterich and Keith Richard-Dinger at the University of California, Riverside. The original code was developed to simulate tectonic earthquakes and slow slip events on faults. NRAP has extended the code to simulate induced events by incorporating time-dependent pore pressure changes resulting from fluid injection. EMPSYN is a publically available Fortran program originally developed at Lawrence Livermore National Laboratory (LLNL) (Hutchings, 1994), and has been further developed at Lawrence Berkeley National Laboratory (LBNL) under NRAP to utilize simulated earthquake sources from RSQSim. All three programs can be compiled under Windows, Unix/Linux or Mac OS X operating systems, and are presently integrated within the GNU Unix environment.

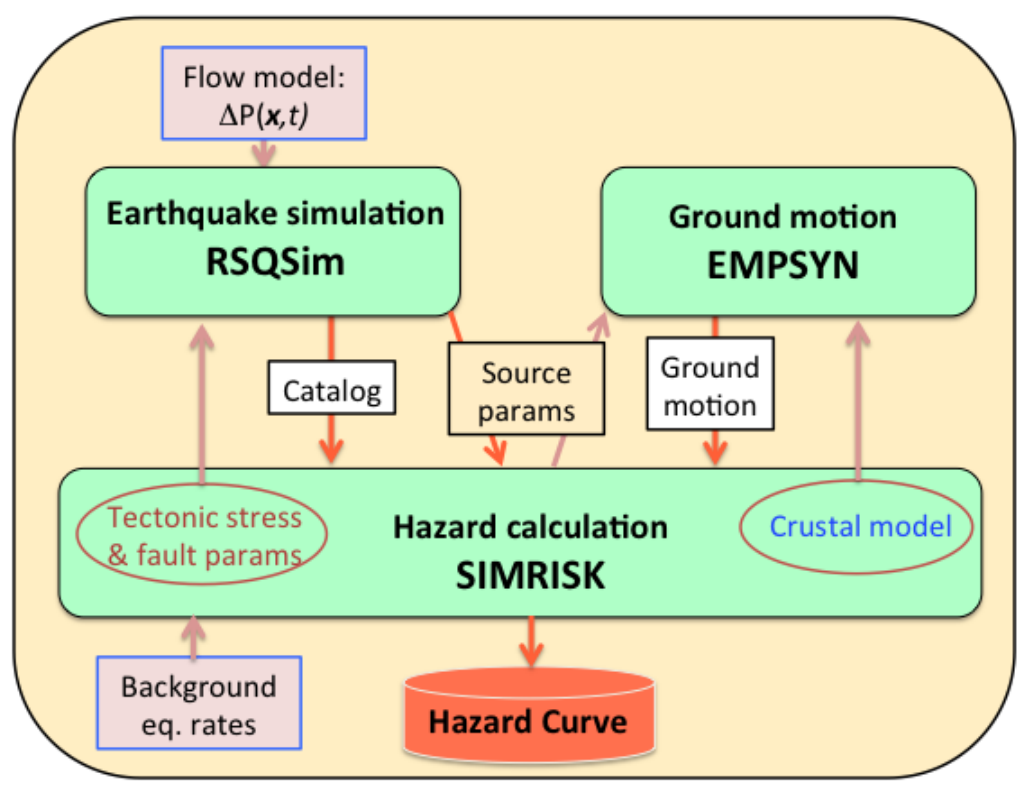

Figure 1: Schematic diagram of the probabilistic seismic hazard computational framework.

SIMRISK generates multiple epistemic realizations of fault frictional properties, geometries and stresses to pass to RSQSim by sampling from input parameter uncertainty distributions. Realizations of local crustal seismic P- and S-wave velocity and attenuation structures are likewise generated and passed to EMPSYN. Stochastic (aleatory) uncertainty is accounted for by sampling from specified random distributions of fault properties and crustal parameters within each epistemic earthquake and ground motion simulation. 
RSQSim generates a seismicity catalog for each epistemic/aleatory realization by simulating earthquake sequences on the faults and fractures in the source model. The simulations are driven by tectonic shear loading utilizing a laboratory-derived slip-rate and fault state frictional law (Dieterich and Richards-Dinger, 2010; Dieterich, 1995). Earthquakes are induced by modeling the evolving pore-pressure field that arises from fluid injection, which modifies the distributions of effective stress on the fault surfaces over time. The locations, times, and source parameters of the earthquakes in the catalog are passed to SIMRISK at the conclusion of each simulation. SIMRISK then selects a statistically representative subset of the earthquake catalog using a Latin hypercube approach and calculates a frequency-magnitude distribution. The occurrences of the earthquakes in the catalog are calibrated by requiring the long-term rates of occurrence, calculated over time periods which are much longer than the duration of the pore pressure perturbation, to match observed background tectonic rates.

EMPSYN calculates ground accelerations and velocities by convolving the source parameters of each earthquake in the catalog subset with source-site Green's functions synthesized from the crustal structure. The Green's functions are calculated using the frequency-wavenumber program FKRPROG (Saikia, 1994). SIMRISK then constructs the hazard curve for that epistemic realization by combining the calculated ground motions with the earthquake occurrence rates. The full uncertainty distribution on the hazard curve is built by running a large number (typically several thousand) of epistemic realizations.

The PSHA framework is designed so that the RSQSim module can be replaced by alternative methods of calculating earthquake occurrence statistics. These include time- and spacedependent empirical frequency-magnitude relations derived from induced microearthquakes recorded by a local monitoring network once $\mathrm{CO}_{2}$ injection is underway (e.g. Bachmann et al, 2011). (C. Bachmann is continuing to develop such relations as part of the LBNL/NRAP effort.) Similarly, the EMPSYM module can be replaced by empirical ground motion prediction equations for small magnitude earthquakes at short distances that are currently under development; these include, for example, those for enhanced geothermal projects being developed by the European Commission GEISER project (www.geiser-fp7.eu) (Douglas et al., 2012). 


\section{RESULTS}

We have applied the first-generation toolset to a hypothetical single-fault scenario using realistic $\mathrm{CO}_{2}$ storage reservoir properties. Specifically, we used a subsurface model of the storage reservoir and overburden that is based on characteristics derived from the reservoir used for carbon storage at In Salah, Algeria. Petrophysical and other physical properties known at the site are used in the geologic model, and the reservoir pressure response to injection is based on a model of the actual reservoir with realistic operational parameters. A fault with hypothetical properties was added to the geologic model for purposes of testing the first-generation toolset. The fault is not intended to represent any real feature at In Salah. This application is intended only as an end-to-end demonstration of the integrated induced seismicity PSHA toolset and does not at this stage reflect a comprehensive application of the model to identify general relationships that might guide operational strategies.

The fault geometry is shown schematically in Figure 2. The fault was inserted into the 3D geologic model of the site at the top of the reservoir level (1780 m depth) close to one of the injection wells, and for the purpose of the demonstration is assumed to extend $895 \mathrm{~m}$ and $620 \mathrm{~m}$ above and below the top of the reservoir, respectively. The fault was assigned a long-term slip rate of $1 \mathrm{~mm} / \mathrm{yr}$, from which the tectonic shear-stressing rate was calculated.

The seismicity simulation was carried over a total time period of 5,000 years. The pore pressure on the fault was hydrostatic prior to initiation of injection. Beginning at 520 years, a time- and space-dependent pore pressure field on the fault was input from a simplified NUFT flow model based on the injection history in the well closest to the fault. Pore pressures on the fault rise linearly to peak values at 522 years and then the pressure distribution shown in Figure 2 remains constant for the next 18 years before pressures fall gradually back to hydrostatic.
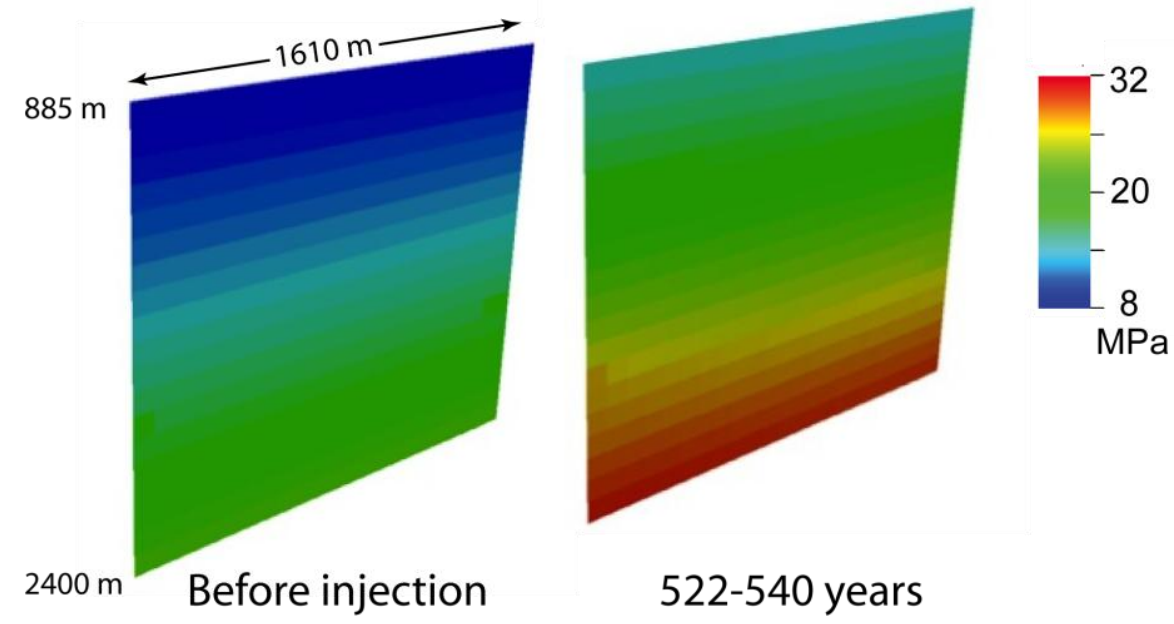

Figure 2: Fault geometry showing pore pressure distributions before (hydrostatic) and at the peak of injection.

Parameter values used in the earthquake simulations are summarized in Table 1. Initial static normal and shear stresses resolved on the fault were calculated from depth profiles of the in situ tectonic stress field estimated from In Salah well logs. Elastic parameters and seismic P- and Swave velocities were likewise estimated from available well data. Distributions of other parameters of the rate-and-state frictional law are adopted from generic values appropriate to the shallow crustal depths at which the induced events occur (e.g. Marone, 1998). 
Table 1: Earthquake source and ground motion simulation parameter values

\begin{tabular}{|l|l|l|}
\hline \multicolumn{1}{|c|}{ Parameter } & \multicolumn{1}{c|}{ Value } & \multicolumn{1}{c|}{ Data source } \\
\hline $\mathrm{v}_{\mathrm{p}}$ & $3.80 \mathrm{~km} \cdot \mathrm{s}^{-1}$ & In Salah well Kb-502 sonic log \\
\hline $\mathrm{v}_{\mathrm{s}}$ & $1.96 \mathrm{~km} \cdot \mathrm{s}^{-1}$ & KB-502 sonic log \\
\hline$\mu_{0}$ & $0.6-0.9$ & Generic range \\
\hline$\lambda$ & $18034.0 \mathrm{MPa}$ & Derived from KB-502 well logs \\
\hline$\mu$ & $9290 \mathrm{MPa}$ & Derived from KB-502 well logs \\
\hline$\sigma$ & $17 \mathrm{MPa}$ & Derived from KB-502 well data \\
\hline $\mathrm{d} \sigma / \mathrm{dz}$ & $0.02 \mathrm{MPa} \cdot \mathrm{m}^{-1}$ & Derived from KB-502 well data \\
\hline$\tau$ & $4.0 \mathrm{MPa}$ & Derived from KB-502 well data \\
\hline $\mathrm{V}$ & $1 \mathrm{~mm} \cdot \mathrm{y}^{-1}$ & Assumed hypothetical value \\
\hline fault length & $1.6 \mathrm{~km}$ & Assumed hypothetical value \\
\hline fault down-dip width & $1.5 \mathrm{~km}$ & Assumed hypothetical value \\
\hline $\mathrm{A}$ & 0.005 & Generic value (e.g. Marone, 1998$)$ \\
\hline $\mathrm{b}$ & 0.015 & Generic value \\
\hline $\mathrm{D}_{\mathrm{c}}$ & $25 \mu \mathrm{m}$ & Generic value \\
\hline $\mathrm{V}_{\mathrm{eq}}$ & $1 \mathrm{~m} \cdot \mathrm{s}^{-1}$ & Generic value \\
\hline
\end{tabular}

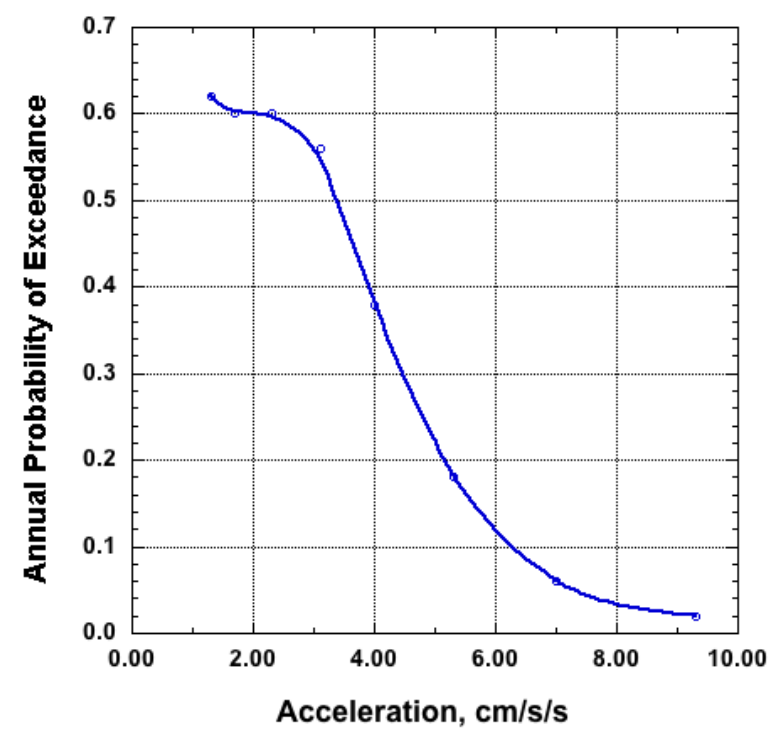

Figure 3: Seismic hazard curve at a surface site approximately $5 \mathrm{~km}$ from the fault.

Figure 3 shows the seismic hazard curve for a surface site located approximately $5 \mathrm{~km}$ from the fault. Each hazard value is the mean annual probability of exceeding the corresponding peak ground acceleration. The curve is the result of one epistemic simulation over a total time period of 5,000 years, during which the maximum observed magnitude is M3.9. This generates a ground acceleration of $9.3 \mathrm{~cm} \cdot \mathrm{s}^{-2}$, or approximately $0.01 \mathrm{~g}$. This level of ground motion might be felt but would not cause structural damage. 


\section{DISCUSSION}

The profile presented in Figure 3 demonstrates an induced seismicity hazard calculation for a realistic scenario based on a specific site characterization and injection history.

As noted, the specific scenario that was simulated is hypothetical in that the geometric and mechanical properties of the fault included in the model are hypothetical, and in particular, its assigned slip rate is significantly higher than rates generally observed on faults in regions like central Algeria that have low tectonic activity. The $1 \mathrm{~mm} / \mathrm{yr}$ slip rate was chosen to generate relatively high earthquake occurrence frequencies for the purpose of the demonstration. These frequencies, together with the maximum magnitude determined by the dimensions of the fault, drive the seismic hazard estimate. The first-generation hazard profile presented here includes only one epistemic realization.

The bulk of the effort in developing the induced seismicity risk methodology to date has been in interfacing the earthquake simulation, ground motion, and hazard calculation modules to construct the PSHA computational framework.

NRAP's next focus is in three areas. First, the toolset will be applied to a range of model conditions to evaluate general trends in the sensitivity of hazard calculations to key parameters and site characteristics. Second, the NRAP toolset will be further developed to allow estimation of hazard over the widely different time intervals ( months to hundreds of years) appropriate to the successive phases of a GCS project. Finally, the next generation of hazard profiles will include full suites of epistemic and aleatory realizations to allow estimation of the hazard uncertainty.

The first-generation PSHA demonstration reported here represents the first step in the development of NRAP's integrated PSRA toolset. The toolset is at present a set of research programs undergoing continued development. The toolset will be applied to a range of injection scenarios to investigate systematically the dependence of seismic hazard and risk on site characteristics and injection parameters, such as rock properties, distributions of fractures and faults, reservoir depth, and injection rate and pressure. The overall objective is to provide a fully documented methodology that can be adopted by operators and other parties to carry out PSRA for individual GCS sites. This will be accompanied by a prototype software package that can be used by downstream users as a template. As described in Section 3 above, the design of the PSHA/PSRA framework will allow alternative earthquake-frequency and ground motion program modules to be interfaced to the SIMRISK core. SIMRISK and the modules currently implemented are written in standard programming languages (Fortran and C), which can be compiled on all common platforms and are relatively easy to integrate within a mixed-language programming environment. The intention is to make the prototype SIMRISK core and EMPSYN-based ground motion module available to others, and it is anticipated that stand-alone programs such as RSQSim that are used as modules will be released by their authors in the future. 


\section{REFERENCES}

Bachmann, C.; Wiemer, S.; Woessner, J.; Hainzl, S. Statistical Analysis of the Induced Basel 2006 Earthquake Sequence: Introducing a Probability-based Monitoring Approach for Enhanced Geothermal Systems. Geophys. J. Int. 2011, 186, 793-807.

Dieterich, J. Earthquake Simulations with Time-dependent Nucleation and Long-range Interactions. Nonlinear Processes in Geophysics 1995, 2, 109-120.

Dieterich, J.; Richards-Dinger, K. Earthquake Recurrence in Simulated Fault Systems. Pure App. Geophys. 2010, 167, 1087-1104.

Douglas, J.; Edwards, B.; Convertito, V.; Sharma, N.; Tramelli, A.; Kraaijpoel, D.; Mena., B.; Maercklin, N.; Troise, C. Predicting ground motion from induced earthquakes in geothermal areas. Submitted to Bull. Seismol. Soc. Am. 2012.

Hutchings, L. Kinematic Earthquake Models and Synthesized Ground Motion using Empirical Green's Functions. Bull. Seismol. Soc. Am. 1994, 84, 1028-1050.

Marone, C. Laboratory-derived Friction Laws and their Application to Seismic Faulting. Ann. Rev. Earth. Planet. Sci. 1998, 26, 643-696.

Richards-Dinger, K.; Dieterich, J. RSQSim Earthquake Simulator. Seismol. Res. Let. 2012, 83, 983-990.

Saikia, C. Modified Frequency-wavenumber Algorithm for Regional Seismograms using Filon's Quadrature: Modeling of Lg Waves in Eastern North America. Geophys. J. Int. 1994, $118,142-158$. 
This page intentionally left blank. 


\section{NRAP}

NRAP is an initiative within DOE's Office of Fossil Energy and is led by the National Energy Technology Laboratory (NETL). It is a multi-national-lab effort that leverages broad technical capabilities across the DOE complex to develop an integrated science base that can be applied to risk assessment for long-term storage of carbon dioxide $\left(\mathrm{CO}_{2}\right)$. NRAP involves five DOE national laboratories: NETL Regional University Alliance (NETL-RUA), Lawrence Berkeley National Laboratory (LBNL), Lawrence Livermore National Laboratory (LLNL), Los Alamos National Laboratory (LANL), and Pacific Northwest National Laboratory (PNNL). The NETL-RUA is an applied research collaboration that combines NETL's energy research expertise in the Office of Research and Development (ORD) with the broad capabilities of five nationally recognized, regional universities - Carnegie Mellon University (CMU), The Pennsylvania State University (PSU), University of Pittsburgh (Pitt), Virginia Polytechnic Institute and State University (VT), and West Virginia University (WVU) - and the engineering and construction expertise of an industry partner (URS Corporation).

\section{Technical Leadership Team}

Jens Birkholzer

LBNL Technical Coordinator

Lawrence Berkeley National Laboratory

Berkeley, CA

\section{Grant Bromhal}

NETL Technical Coordinator

Lead, Reservoir Performance Working Group

Office of Research and Development

National Energy Technology Laboratory

Morgantown, WV

\section{Chris Brown}

PNNL Technical Coordinator

Pacific Northwest National Laboratory

Richmond, WA

\section{Susan Carroll}

LLNL Technical Coordinator

Lawrence Livermore National Laboratory

Livermore, CA

\section{William Foxall}

Lead, Induced Seismicity Working Group

Lawrence Livermore National Laboratory

Livermore, CA

\section{Diana Bacon}

Lead, Groundwater Protection Working Group

Pacific Northwest National Laboratory

Richmond, WA

\section{Tom Daley}

Lead, Strategic Monitoring Working Group

Lawrence Berkeley National Laboratory

Berkeley, CA

George Guthrie

Technical Director, NRAP

Office of Research and Development

National Energy Technology Laboratory

Pittsburgh, PA

\section{Rajesh Pawar}

LANL Technical Coordinator

Lead, Systems/Risk Modeling Working Group

Los Alamos National Laboratory

Los Alamos, NM

\section{Tom Richard}

Deputy Technical Director, NRAP

The Pennsylvania State University

NETL-Regional University Alliance

State College, PA

\section{Brian Strazisar}

Lead, Migration Pathways Working Group

Office of Research and Development

National Energy Technology Laboratory

Pittsburgh, PA 
Sean Plasynski

Deputy Director

Strategic Center for Coal

National Energy Technology Laboratory

U.S. Department of Energy

\section{Jared Ciferno}

Director

Office of Coal and Power R\&D

National Energy Technology Laboratory

U.S. Department of Energy

Robert Romanosky

Technology Manager

Crosscutting Research

National Energy Technology Laboratory

U.S. Department of Energy

\section{Regis Conrad}

Director

Division of Cross-cutting Research

Office of Fossil Energy

U.S. Department of Energy
NRAP Executive Committee

Cynthia Powell

Director

Office of Research and Development

National Energy Technology Laboratory

U.S. Department of Energy

Alain Bonneville

Laboratory Fellow

Pacific Northwest National Laboratory

Donald DePaolo

Associate Laboratory Director

Energy and Environmental Sciences

Lawrence Berkeley National Laboratory

Melissa Fox

Chair, NRAP Executive Committee

Program Manager

Applied Energy Programs

Los Alamos National Laboratory

\section{Julio Friedmann}

Chief Energy Technologist

Lawrence Livermore National

Laboratory

George Guthrie

Technical Director, NRAP

Office of Research and Development

National Energy Technology Laboratory
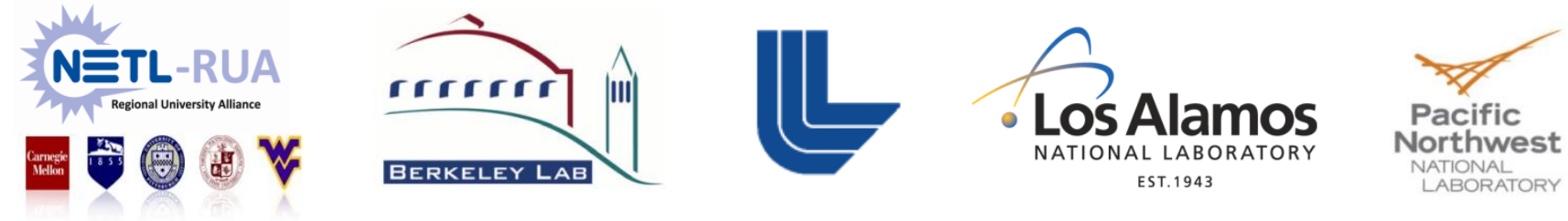